\title{
The dawn of post antibiotic era: Are we prepared?
}

\section{Joshi A}

Aishana Joshi, Managing Editor, Journal of Kathmandu Medical College, Kathmandu, Nepal

T. The word antibiotic has its historic language of origin in Greek; anti meaning against and bios meaning life. Though the literal meaning of antibiotic is against life; in the field of medicine, 'life' has been a metaphor for microbes ever since the discovery of antibiotics in the early $20^{\text {th }}$ century. In 1928 , there was a major breakthrough in the field of medicine after the first antibiotic Penicillin was discovered by Sir Alexander Fleming, an observant clinical bacteriologist from Scotland ${ }^{1}$. The discovery of Penicillin had marked the dawn of antibiotic era changing the age old evolutionary relationship between humans and microbes like never before. Following Fleming's evolutionary trajectory, the scientists all over the world embarked on to discourse on the miracle drug of the $20^{\text {th }}$ century which led to the discovery of several other antibiotics. The extensive use of antibiotic thus, began as a novel therapeutic agent as it had an immense role in saving millions of lives marking the human triumph over the microbes; the bacteria had seemingly lost the battle against humans but ironically they had not conceded the war.

Antibiotics or precisely the antimicrobial substance as termed lately are amongst the most frequently prescribed medications in modern medicine. With a wide array of antibiotics available commercially and a great diversity of treatment they confer, the use of antibiotics has been in tremendous rise in recent years. Over the past few decades, there has been a global upsurge in the use of antibiotics with a dramatic rise in their misuse resulting in the horrendous problem of antibiotic resistance ${ }^{2,3}$. In less than a century after the discovery of the first antibiotic Penicillin, the rapid emergence of multi to extensively drug resistant bacterial strains often termed as 'super bugs' has led to the global problem of antibiotic resistance which had not been anticipated even by the legendary Physician Fleming, imposing one of the greatest challenges to the

\section{Address for correspondence}

Dr. Aishana Joshi

Managing Editor

Journal of Kathmandu Medical College

Sinamangal, Kathmandu, Nepal

E-mail: aishanajoshi@gmail.com global medical community. In recent years, an emerging faction of antibiotic resistant bacteria abbreviated as ESKAPE (Enterococcus faecium, Staphylococcus aureus, Klebsiella pneumoniae, Acinetobacter baumannii, Pseudomonas aeruginosa and Enterobacter species) has been identified as being capable of escaping the biocidal action of antibiotics posing serious therapeutic dilemma to the global medical community ${ }^{4,5}$. The global crisis of antibiotic resistance has largely been attributed to indiscriminate and inappropriate use of antibiotics in hospitals, outpatient clinics and communities. Over prescription, under prescription, self prescription, non compliance, over the counter use, empirical antibiotic therapy, sharing of antibiotics among one another, using antibiotics from previous prescriptions, irrational prescription of mighty antibiotics intended for rapid cure have all contributed to antibiotic resistance, the most dreaded aftermath of antibiotic misuse. Doctors seem to be tempted in prescribing antibiotics as impulsively as their patients who are tempted to receive them. But why do doctors prescribe antibiotics when they are not needed at all? One of the reasons for this might be the fear of being referred to as professionally incompetent doctor by the patients and the feeling of insecurity on being questioned for not prescribing antibiotics for their ailments. Another reason could be less time to hand out a prescription to the incredulous patients than to explain them why one is not needed. The patients also have an interesting tendency to look at antibiotics in a different way; the common notion that prevails is that there is nothing harm in taking some pills, so why not take them? Adding to this doctor patient dilemma on use of antibiotics, the problem of resistance has been compounded by the indiscriminate use of antibiotics in agriculture and livestock farms, where they are frequently used for idiosyncratic results ${ }^{6,7}$.

The insurmountable problem of antibiotic resistance has now threatened on the future use of antibiotics to a larger extent. The dearth of new drugs that can fight against the resistant strains has further magnified the problem of resistance threatening the prevention and effective treatment of ever increasing range of infections. In past few decades, several studies have reported the global 
emergence of pan drug resistant organisms which are easily transmitted from one person to another ${ }^{8-10}$. The new forms of resistant bugs will require new drugs that are yet to be discovered. The invention of new drugs is a challenging task for it demands tremendous amount of resources and technology. If none of the hitherto drugs work, virtually we will be living in the world without armamentarium against microbes marking the dawn of post antibiotic era. The rational use of antibiotics has long been a matter of debate but defining the term 'rational' is again a rigorous task. The only way we can think of at this point is restricting the use of antibiotics only when its requirement can be assured. Every individual should be made aware that every time we are taking the drug unnecessarily, we are adding to the overall problem of resistance. The health care workers in collaboration with stakeholders should make coordinated efforts with augmentation of research and development of optimal strategies for use of antibiotics to fight against this dreaded problem of antibiotic resistance to at least slow the process if full control cannot be achieved.

\section{REFERENCES}

1. Fleming A. The discovery of penicillin. British Medical Bulletin. 1944 Jan 1;2(1):4-5.

2. Kardas P, Devine S, Golembesky A, Roberts C. A systematic review and meta-analysis of misuse of antibiotic therapies in the community. International journal of antimicrobial agents. 2005 Aug 31; 26(2):106-13.

3. Carey B, Cryan B. Antibiotic misuse in the community-a contributor to resistance?. Irish medical journal. 2003 Feb;96(2):43-44.

4. Pendleton JN, Gorman SP, Gilmore BF. Clinical relevance of the ESKAPE pathogens. Expert review of anti-infective therapy, 2013 Mar 1;11(3):297-308.

5. Boucher HW, Talbot GH, Bradley JS, Edwards JE, Gilbert $D$ et al. Bad bugs, no drugs: no ESKAPE! An update from the Infectious Diseases Society of America. Clinical Infectious Diseases; 2009 Jan 1;48(1):1-2

6. Hardy B. The issue of antibiotic use in the livestock industry: what have we learned?. Animal biotechnology. 2002 Jul 1;13(1):129-47.

7. Khachatourians GG. Agricultural use of antibiotics and the evolution and transfer of antibiotic-resistant bacteria. Canadian Medical Association Journal. 1998 Nov 3;159(9):1129-36.

8. Kumarasamy KK, Toleman MA, Walsh TR, Bagaria J, Butt $F$ et al. Emergence of a new antibiotic resistance mechanism in India, Pakistan, and the UK: a molecular, biological, and epidemiological study. The Lancet infectious diseases. 2010 Sep 30;10(9):597-602.

9. Souli M, Galani I, Giamarellou H. Emergence of extensively drug-resistant and pandrug-resistant Gram-negative bacilli in Europe. Euro surveill. 2008 Nov 20;13(47):19045.

10. Falagas ME, Bliziotis IA. Pandrug-resistant Gramnegative bacteria: the dawn of the post-antibiotic era?. International journal of antimicrobial agents. 2007 Jun 30;29(6):630-6. 